\title{
Errata
}

\section{Ionic Character}

\author{
N. C. BAIRD and M. A. WhITEHEAD \\ Theoret. chim. Acta (Berl.) 2, 259 (1964)
}

p. 262, Tab. 2: The values of $E_{v}, b^{*}$ and $c^{*}$ should read:

for $B e^{-}:-0.95,+0.71,-0.56$ resp.

for $B^{-}:-5.32,+4.25,-3.19$ resp.

p. 263, Tab. 3: "This Paper" ionic character values for

$\mathrm{NaH}, \mathrm{HCl}, \mathrm{HBr}, \mathrm{HI}, \mathrm{FCl}, \mathrm{BrCl}$ should be

$25.0,9.2,5.5,4.2,9.7,4.8 \%$ resp.

The "Gordy" ionic characters of $\mathrm{HBr}, \mathrm{HI}, \mathrm{BrCl}$ are

$20.5,15.5,16.5 \%$ resp.

\section{Group Orbital Electronegativities}

\section{A. Whitehead, N. C. BatRd and M. Kaplanskx}

Theoret. chim. Acta (Berl.) 3, 135 (1965)

p. 140, Eq. (4) should read:

$$
c_{B}=0.5\left(\delta_{B}-\alpha_{B}\right)+0.5\left(n_{T^{(1)}}\right)\left(\varepsilon_{B}-\beta_{B}\right)+0.5\left(n_{\left.\left.T^{(}\right)\right)^{2}}\left(\zeta_{B}-\gamma_{B}\right) .\right.
$$

p. 142, Tab. 5: The fifth column heading is $\varrho \mathrm{C}^{35}$ rather than $n_{\mathrm{Cl}}{ }^{35}$.

Corrected $E_{v y}$ parameters for $\mathrm{C}$ (tetetete), $\mathrm{C}($ trtrtr $\pi)$ and the improved data for benzene are listed in Tab. 1 and 6 of N. C. BaTRD and M. A. WhITEHEAd's paper: Theoret. chim. Acta 6, 167 (1966).

We regret misspelling Dr. B. P. DAILEY's name in the references. 